\title{
Anxiety and depression in Nepal: prevalence, comorbidity and associations
}

Ajay Risal ${ }^{1,2^{*}}$, Kedar Manandhar ${ }^{1,2}$, Mattias Linde ${ }^{1,3}$, Timothy J. Steiner ${ }^{1,4}$ and Are Holen ${ }^{1,5}$

\begin{abstract}
Background: Anxiety and depression are two important contributors to the global burden of disease. In many developing countries, including Nepal, their prevalences are yet to be assessed.

Methods: A nationwide cross-sectional study was conducted among a representative sample of Nepalese adults aged 18-65 years $(N=2100)$, selected by multistage random cluster sampling and interviewed at home during unannounced visits. The validated questionnaires included the Hospital Anxiety and Depression Scale (HADS), to detect cases of anxiety (HADS-A), depression (HADS-D) and comorbid anxiety and depression (HADS-CAD), the Eysenck Personality Questionnaire Revised Short Form-Neuroticism (EPQRS-N), and the World Health Organization Quality of Life 8-question scale (WHOQOL-8). Logistic regression analyses were used to explore associations of caseness with four groups of variables: demographic, domicile, substance use, and behavioural and health.
\end{abstract}

Results: Age- and gender-adjusted point prevalences of HADS-A, HADS-D and HADS-CAD were 16.1, 4.2 and $5.9 \%$ respectively. In a multivariate model, HADS-A was positively associated with urban residence $(A O R=1.82 ; p<0.001)$ and neuroticism ( $A O R=1.32 ; p<0.001)$, and negatively with alcohol consumption ( $A O R=0.71 ; p=0.041)$. HADS-D was positively associated with marijuana use $(A O R=3.61 ; p=0.017)$ and negatively with quality of life (QoL) $(\mathrm{AOR}=0.86 ; p<0.001)$. HADS-CAD was positively associated with widowhood (AOR $=2.71 ; p=0.002)$, urban residence $(A O R=2.37 ; p=0.001)$, living at altitude $\geq 2000 m(A O R=2.32 ; p=0.002)$ and neuroticism $(A O R=1.26$; $p<0.001)$, and negatively with alcohol use (AOR $=0.56 ; p=0.026)$ and $\mathrm{QoL}(\mathrm{AOR}=0.79 ; p<0.001)$.

Conclusion: Depression and anxiety are important mental health conditions in Nepal, and major contributors to public ill health, being very highly prevalent, comorbid and associated with psychosocial burden. They are also linked to the unique topography, habitation and social structure of the country. High prevalence coupled with the disabling nature of these disorders establishes their health-care priority and their importance in national health policy.

Keywords: Anxiety, Depression, Developing countries, Health policy, Mental health, Neuroticism, Public health, South Asia, Urbanization, Widowhood

\section{Background}

Anxiety and depression embrace a range of mental conditions occurring frequently in primary health care, usually in the form of overt disorders. They are acknowledged as common mental disorders (CMDs) [1,2] and, in terms of their ubiquity and the burdens they impose, as major disorders of the brain [3]. In the recent Global Burden of Disease Study 2013 (GBD 2013), while

\footnotetext{
* Correspondence: ajay.risal@ntnu.no

${ }^{1}$ Department of Neuroscience, Norwegian University of Science and Technology (NTNU), Trondheim, NO 7491, Norway

2Dhulikhel Hospital, Kathmandu University Hospital, Dhulikhel, Kavre, Nepal

Full list of author information is available at the end of the article
}

mental and substance use disorders collectively accounted for $21.2 \%$ of all years of life lost to disability (YLDs) [4], depression and anxiety were ranked second and ninth highest specific causes of YLDs in both developed and developing countries. These disorders are therefore of considerable public-health importance [5] in highincome $[6,7]$ and low- and middle-income (LAMI) countries [8] alike. They are also highly comorbid [9].

Extrapolations from GBD 2013 data indicate that depression and anxiety are among the top ten causes of YLDs in South Asia, which includes Nepal [4]; however, no research has been undertaken to make direct national 
estimates in this Region. Available studies were limited to a few scattered health centres [10, 11], districts [12-14], villages [15] or cities [16], and could not comprehensively describe the prevalence of CMDs, let alone provide an account of the burdens attributable to them.

With these factors under consideration, our principal aim was to assess health-care needs by estimating the prevalences of anxiety and depression in Nepal, using a well-validated and culturally-adapted screening instrument [17]. Also, we wished to establish their degree of comorbidity, as well as their associations with sociodemographic characteristics, social behaviours and healthrelated factors. This would fill current knowledge gaps regarding these CMDs in the South Asian Region, and serve our overall purpose of guiding public-health policy towards better mental health in Nepal.

There were methodological issues to be considered. Most earlier South Asian studies utilized self-report scales with caseness of anxiety [10, 12] or depression [13-15] being indicated by summed scores at or above defined thresholds. Such scales are useful in areas with inadequate or unevenly distributed resources that greatly limit epidemiological surveys [18]. This was certainly true of Nepal, one of the poorest nations of the world [19]. Furthermore, its geographical and sociocultural diversities posed unique logistic and methodological difficulties which our survey had to overcome [20, 21]. We considered important the relationships between mental wellbeing and behaviours typical of life and culture in the Nepalese community [20], such as the use of alcohol and marijuana during festivals, and the common method of carrying heavy loads on the back, suspended by a tumpline around the forehead. We also considered personality traits associated with psychopathology (neuroticism), and measures of burden in the face of hardship ("life toughness"), including impairment of quality of life (QoL), since these might be pertinent. In selecting covariates for analysis of associations, we had no previous research to draw upon. However, the data were gathered in the context of a nationwide survey of headache disorders [22, 23], which incorporated a range of demographic, environmental and health variables.

\section{Methods}

\section{Ethics}

This study was part of a larger research project addressing the major disorders of the brain in Nepal [20], approved by the Nepal Health Research Council (NHRC), the Institutional Review Committee of Kathmandu University School of Medical Sciences, Dhulikhel Hospital, and the Regional Committee for Health and Research Ethics in Central Norway. Informed consent was given by all participants and confirmed either by signature or by fingerprint.

\section{Study design and sampling}

This was a cross-sectional study in which unannounced household visits were made during May 2013 by trained interviewers using structured questionnaires. To obtain a representative sample of the adult general population, we used a multistage random cluster-sampling technique to select households in all three physiographic divisions of the country and, within each division, all five development regions (Far-Western, Mid-Western, Western, Central and Eastern). From each household we randomly selected one adult aged 18-65 years. This procedure has been explained in more detail elsewhere [21].

\section{Study instruments}

\section{Hospital Anxiety and Depression Scale (HADS)}

We used a validated Nepali translation of HADS [17] to estimate the prevalence of anxiety and depression. HADS consists of 14 items in two subscales: HADSAnxiety and HADS-Depression, each of seven items. In relation to each item, participants report their subjective experience during the preceding week, which is rated 0-3 (3 indicating maximum symptom severity). The sum of each subscale has a potential range of 0-21. As recommended in the original English version [24], and validated in the Nepali translation [21], we used a threshold of 11 on the respective subscale to indicate caseness for anxiety or depression.

\section{Eysenck personality questionnaire revised short form- neuroticism (EPQRS-N)}

We used a validated Nepali translation of EPQRS-N [25] to assess the degree of neuroticism [26] in the survey participants. EPQRS-N has 12 items, each a question with response options "No" (scored 0) and "Yes" (scored 1). The sum of responses has a potential range of $0-12$, higher values indicating more neuroticism.

\section{World Health Organization Quality-of-Life 8-question scale (WHOQOL-8)}

The culturally adapted version of WHOQOL-8 [27] was also used. This instrument consists of eight questions addressing perceived aspects of a person's QoL: satisfaction with health and with oneself, the ability to perform daily activities, personal relations and living conditions, the sense of subjective adequacy of available resources, and the sense of having enough energy and means to meet one's needs. Each question has five response options on a Likert scale, and is scored from 1 (worst) to 5 (best); the summed score has the potential range of $8-$ 40. Higher total scores indicate better QoL.

\section{HARDSHIP questionnaire}

All these instruments were incorporated as modules into the Headache-Attributed Restriction, Disability, Social 
Handicap and Impaired Participation (HARDSHIP) questionnaire. This instrument was originally designed to be administered by trained lay interviewers for assessing headache disorders [28], and in our study it was translated and culturally adapted for Nepal [29]. Separate sections covered demographic characteristics (age, gender, marital status and household consumption), household location (urban or rural, and altitude), use of substances (alcohol, tobacco and marijuana), tumpline use (frequency and heaviness of load), height and weight (from which body mass index [BMI] was computed) and blood pressure (BP). Finally, we included a question on life-toughness, with five ordinal response options from "very easy" to "very tough".

\section{Statistical analysis}

Analyses were carried out using IBM SPSS Statistics 21.

We used caseness as defined by HADS to compute the crude prevalences of anxiety and depression. Participants scoring above the thresholds of both subscales were considered as cases of comorbid anxiety and depression (cAD). In order to examine associations, we separated HADS-cAD cases from participants scoring above the thresholds only for anxiety (HADS-A cases) or only for depression (HADS-D cases). Since HADS takes account only of very recent subjective experience (in the past week) [24], prevalence estimates approximate to point prevalences. Thus we calculated the point prevalences of anxiety, depression, HADS-A, HADS-D and HADScAD, reporting the estimates as percentages with $95 \%$ confidence intervals (CIs). Our sample was underrepresented by young males aged 18-34 years in comparison to the recent national population census of Nepal [21]. Hence, we adjusted our observed estimates by standardization according to the age and gender distributions of the national population [30].

We used bivariate logistic regression to identify associations with the categorical variables: demographic characteristics including age (categorized 18-25, 26-35, 36$45,46-55,56-65$ years), habitation (urban or rural), altitude of domicile $(<2000$ or $\geq 2000 \mathrm{~m})$, use of substances (yes/no for each of alcohol, tobacco and marijuana), factors related to tumpline use (frequency: never, sometimes or daily; heaviness of load [assessed subjectively]: light, moderate or heavy), life-toughness (assessed subjectively: easy, medium or tough), BP and BMI. We categorized $\mathrm{BP}$ as hypertensive or non-hypertensive according to the Joint National Committee on Prevention, Detection, Evaluation, and Treatment of High Blood Pressure criteria (JNC7) [31]. BMI was categorized as underweight $(<18.5)$, normal $(18.5-24.99)$ or overweight $(\geq 25)$ [32]. We used Pearson correlation to test associations between HADS-Anxiety and HADSDepression total scores and continuous variables: neuroticism and WHOQOL-8 scores. In view of the high number of participants relative to the number of variables in the analyses, we set the level of significance at $p<0.05$.

Variables that showed no significant associations in bivariate analyses were excluded from multivariate analyses. The remaining variables were divided into four blocks and entered into logistic regression analyses: demographic (age and gender) in block A, domicile (habitation and altitude) in block B, substance use in block $\mathrm{C}$ and behavioural and health variables (tumpline use, life toughness, neuroticism and WHOQOL-8) in block D. Adjusted odds ratios (AORs) with $95 \%$ CI for each independent variable were calculated. Age was used as a continuous variable in the multivariate computations. Prevalences of the three derived types of caseness, HADSA, HADS-D and HADS-cAD, were the dependent variables.

\section{Results}

The total sample included 2100 participants (males: 861

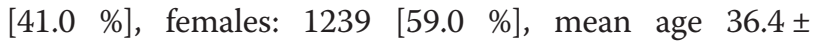
12.8 years). The participation rate was $99.6 \%$. There were no missing data.

\section{Prevalence}

The crude prevalence of anxiety was $22.7 \%$ and of depression $11.7 \%$. The age- and gender-adjusted prevalence of HADS-A was $16.1 \%$, of HADS-D $4.2 \%$ and of HADS-cAD 5.9 \% (Table 1).

\section{Associations}

Anxiety caseness and depression caseness were very strongly associated $(\mathrm{OR}=5.6$ [95 \% CI: 4.2-7.4]; $p<$ $0.001)$. We arrived at this result either by taking HADSA + HADS-cAD (all anxiety) as the independent variable and HADS-D + HADS-cAD (all depression) as the dependent, or by the reverse analysis (depression independent, anxiety dependent).

In the bivariate analysis (Table 2), HADS-A was significantly more prevalent among females $(\mathrm{OR}=1.4)$. It

Table 1 Point prevalences (\%) of each disorder according to caseness as defined (see text) $(N=2100)$

\begin{tabular}{lllll}
\hline Caseness & \multicolumn{4}{l}{ Point prevalence } \\
\cline { 2 - 5 } & $n$ & $\%$ & $95 \% \mathrm{Cl}$ & \multicolumn{2}{l}{ Age- and gender-adjusted $^{\mathrm{a}}(\%)$} \\
\hline Anxiety & 477 & 22.7 & $20.9-24.5$ & - \\
Depression & 246 & 11.7 & $10.3-13.1$ & - \\
HADS-A & 340 & 16.2 & $14.6-17.8$ & 16.1 \\
HADS-D & 109 & 5.2 & $4.2-6.1$ & 4.2 \\
HADS-CAD & 137 & 6.5 & $5.4-7.5$ & 5.9 \\
\hline
\end{tabular}

adjusted for age and gender according to the Nepal Population Report, 2011 [30] 
Table 2 Bivariate analyses of associations of caseness by HADS-A, HADS-D and HADS-CAD with categorical demographic, environmental and behavioural factors

\begin{tabular}{|c|c|c|c|c|c|c|c|c|c|c|}
\hline \multirow[t]{3}{*}{ Variable } & \multirow[t]{3}{*}{$N$} & \multicolumn{3}{|c|}{ HADS-A $(n=340)$} & \multicolumn{3}{|c|}{ HADS-D $(n=109)$} & \multicolumn{3}{|c|}{$\operatorname{HADS}-\mathrm{CAD}(n=137)$} \\
\hline & & Prevalence & OR & $p$ & Prevalence & OR & $p$ & Prevalence & OR & $p$ \\
\hline & & $n(\%)$ & $95 \% \mathrm{Cl}$ & & $n(\%)$ & $95 \% \mathrm{Cl}$ & & $n(\%)$ & $95 \% \mathrm{Cl}$ & \\
\hline \multicolumn{11}{|l|}{ Age (years) } \\
\hline $18-25$ & 489 & $84(17.2)$ & Reference & - & $12(2.5)$ & Reference & - & $20(4.1)$ & Reference & - \\
\hline $26-35$ & 657 & $115(17.5)$ & $1.0[0.8-1.4]$ & 0.89 & $23(3.5)$ & $1.4[0.7-2.9]$ & 0.31 & $30(4.6)$ & $1.1[0.6-2.0]$ & 0.69 \\
\hline $36-45$ & 438 & $65(14.8)$ & $0.8[0.6-1.2]$ & 0.33 & $25(5.7)$ & $2.4[1.2-4.9]$ & 0.014 & $31(7.1)$ & $1.8[1.0-3.2]$ & 0.049 \\
\hline $46-55$ & 298 & $49(16.4)$ & $0.95[0.6-1.4]$ & 0.79 & $26(8.7)$ & $3.8[1.9-7.7]$ & $<0.001$ & $28(9.4)$ & $2.4[1.3-4.4]$ & 0.003 \\
\hline $56-65$ & 218 & $27(12.4)$ & $0.7[0.4-1.1]$ & 0.11 & $23(10.6)$ & $4.7[2.3-9.6]$ & $<0.001$ & $28(12.8)$ & $3.5[1.9-6.3]$ & $<0.001$ \\
\hline \multicolumn{11}{|l|}{ Gender } \\
\hline male & 861 & $119(13.8)$ & Reference & - & $42(4.9)$ & Reference & - & $44(5.5)$ & Reference & - \\
\hline female & 1239 & $221(17.8)$ & $1.4[1.1-1.7]$ & 0.014 & $67(5.4)$ & $1.1[0.8-1.7]$ & 0.59 & $93(7.5)$ & $1.5[1.0-2.2]$ & 0.031 \\
\hline \multicolumn{11}{|l|}{ Marital status } \\
\hline married & 1738 & $285(16.4)$ & Reference & - & $92(5.3)$ & Reference & - & $104(6.0)$ & Reference & - \\
\hline single & 239 & $35(14.6)$ & $0.9[0.6-1.3]$ & 0.49 & $5(2.1)$ & $0.4[0.2-0.95]$ & 0.038 & $8(3.3)$ & $0.5[0.3-1.1]$ & 0.10 \\
\hline separated or divorced & 20 & $4(20)$ & $1.3[0.4-3.8]$ & 0.66 & $2(10)$ & $2.0[0.5-8.7]$ & 0.36 & $1(5.0)$ & $0.8[0.1-6.2]$ & 0.85 \\
\hline widowed & 103 & $16(15.5)$ & $0.9[0.5-1.6]$ & 0.82 & $10(9.7)$ & $1.9[1.0-3.8]$ & 0.061 & $24(23.3)$ & $4.8[2.9-7.9]$ & $<0.001$ \\
\hline \multicolumn{11}{|c|}{ Household consumption (USD/year) } \\
\hline$\leq 950$ & 822 & $128(15.6)$ & $1.0[0.8-1.3]$ & 0.97 & $54(6.6)$ & $1.5[1.0-2.3]$ & 0.065 & $54(6.6)$ & $1.1[0.7-1.6]$ & 0.68 \\
\hline $950-1200$ & 806 & $126(15.6)$ & Reference & - & $36(4.5)$ & Reference & - & $49(6.1)$ & Reference & - \\
\hline$>1200$ & 472 & $86(18.2)$ & $1.2[0.9-1.6]$ & 0.23 & $19(4)$ & $0.9[0.5-1.6]$ & 0.71 & $34(7.2)$ & $1.2[0.8-1.9]$ & 0.43 \\
\hline \multicolumn{11}{|l|}{ Habitation } \\
\hline rural & 1328 & $206(15.5)$ & Reference & - & $76(5.7)$ & Reference & - & $84(6.3)$ & Reference & - \\
\hline urban & 772 & $134(17.4)$ & $1.1[0.9-1.5]$ & 0.27 & $33(4.3)$ & $0.7[0.5-1.1]$ & 0.15 & $53(6.9)$ & $1.1[0.8-1.6]$ & 0.63 \\
\hline \multicolumn{11}{|l|}{ Dwelling altitude } \\
\hline$<2000 \mathrm{~m}$ & 1630 & $253(15.5)$ & Reference & - & $71(4.4)$ & Reference & - & $89(5.5)$ & Reference & - \\
\hline$\geq 2000 \mathrm{~m}$ & 470 & $87(18.5)$ & $1.2[0.9-1.6]$ & 0.12 & $38(8.1)$ & $1.9[1.3-2.9]$ & 0.002 & $48(10.2)$ & $2.0[1.4-2.8]$ & $<0.001$ \\
\hline \multicolumn{11}{|l|}{ Tobacco smoking } \\
\hline no & 1613 & $265(16.4)$ & Reference & - & $76(4.7)$ & Reference & - & $91(5.6)$ & Reference & - \\
\hline yes & 487 & $75(15.4)$ & $0.6[0.7-1.2]$ & 0.20 & $33(6.8)$ & $1.5[1.0-2.2]$ & 0.073 & $46(9.4)$ & $1.7[1.2-2.5]$ & 0.003 \\
\hline \multicolumn{11}{|l|}{ Alcohol consumption } \\
\hline no & 1512 & $260(17.2)$ & Reference & - & $77(5.1)$ & Reference & - & $106(7.0)$ & Reference & - \\
\hline yes & 588 & $80(13.6)$ & $0.8[0.6-0.99]$ & 0.045 & $32(5.4)$ & $1.1[0.7-1.6]$ & 0.75 & $31(5.6)$ & $0.7[0.5-1.1]$ & 0.15 \\
\hline \multicolumn{11}{|l|}{ Marijuana use } \\
\hline no & 2065 & $335(16.2)$ & Reference & - & $104(5)$ & Reference & - & $134(6.5)$ & Reference & - \\
\hline yes & 35 & $5(14.3)$ & $0.9[0.3-2.2]$ & 0.76 & $5(14.3)$ & $3.1[1.2-8.3]$ & 0.020 & $8(3.6)$ & $1.4[0.4-4.5]$ & 0.62 \\
\hline \multicolumn{11}{|l|}{ Tumpline use: frequency } \\
\hline never & 801 & $125(15.6)$ & Reference & - & $29(3.6)$ & Reference & - & $46(5.7)$ & Reference & - \\
\hline sometimes & 532 & $89(16.7)$ & $1.1[0.8-1.5]$ & 0.58 & $28(5.3)$ & $1.5[0.9-2.5]$ & 0.15 & $24(4.5)$ & $0.8[0.5-1.2]$ & 0.32 \\
\hline daily & 767 & $126(16.4)$ & $1.1[0.8-1.4]$ & 0.66 & $52(6.8)$ & $1.9[1.2-3.1]$ & 0.005 & $67(8.7)$ & $1.6[1.1-2.3]$ & 0.023 \\
\hline \multicolumn{11}{|c|}{ Tumpline use: heaviness of load } \\
\hline never used & 801 & $125(15.6)$ & Reference & - & $29(3.6)$ & Reference & - & $46(5.7)$ & Reference & - \\
\hline light, moderate & 801 & $116(14.5)$ & $0.9[0.7-1.2]$ & 0.53 & $45(5.6)$ & $1.6[1.0-2.6]$ & 0.06 & $44(5.5)$ & $1.0[0.6-1.5]$ & 0.83 \\
\hline heavy & 498 & 99 (19.9) & $1.3[1.0-1.8]$ & 0.048 & $35(7.0)$ & $2.0[1.2-3.3]$ & 0.007 & $47(9.4)$ & $1.7[1.1-2.6]$ & 0.013 \\
\hline
\end{tabular}


Table 2 Bivariate analyses of associations of caseness by HADS-A, HADS-D and HADS-CAD with categorical demographic, environmental and behavioural factors (Continued)

\begin{tabular}{lllllllllll}
\hline Life toughness & & & & & & & & \\
easy & 417 & $47(11.3)$ & Reference & - & $14(3.4)$ & Reference & - & $11(2.6)$ & Reference & - \\
medium & 1137 & $158(13.9)$ & $1.3[0.9-1.8]$ & 0.18 & $55(4.8)$ & $1.5[0.8-2.7]$ & 0.21 & $49(4.3)$ & $1.7[0.9-3.2]$ & 0.13 \\
tough & 546 & $135(24.7)$ & $2.6[1.8-3.7]$ & $<0.001$ & $40(7.3)$ & $2.3[1.2-4.2]$ & 0.010 & $77(14.1)$ & $6.1[3.2-11.6]$ & $<0.001$ \\
\hline
\end{tabular}

was negatively associated with alcohol use $(\mathrm{OR}=0.8)$, but more prevalent among those reporting the carrying of heavy tumpline loads $(\mathrm{OR}=1.3)$ and among those who felt that life was tough $(\mathrm{OR}=2.6)$. HADS-Anxiety total scores correlated positively with neuroticism $(r=0.57$; $p<0.001)$ and negatively with WHOQOL-8 $(r=-0.45 ; p<$ $0.001)$.

In the multivariate analysis, the association with female gender did not survive, but the negative association with alcohol use did (AOR $=0.7$ [95 \% CI: 0.5-0.98]; $p=$ 0.041). Additionally, a strong association emerged with urban habitation $(\mathrm{AOR}=1.8$ [95 \% CI: 1.3-2.5]; $p<$ $0.001)$. A modest negative association with daily tumpline use $(\mathrm{AOR}=0.7$ [95 \% CI: 0.4-0.97]; $p=0.033)$ replaced the positive association with heavy tumpline loads. The prevalence of HADS-A was higher among high scorers on neuroticism (AOR = 1.3 [95 \% CI: 1.3-1.4]; $p<$ 0.001 ) but the negative association with WHOQOL-8, although significant, was very weak $(\mathrm{AOR}=0.95[95 \% \mathrm{CI}$ : 0.9-0.99]; $p=0.009$ ).

HADS-D in the bivariate analysis (Table 2) showed a strongly ascending trend with age, the association being significant after age 35. HADS-D in this analysis was more prevalent among the high-altitude dwellers $(\mathrm{OR}=$ 1.9), marijuana users $(\mathrm{OR}=3.1)$, daily tumpline users $(\mathrm{OR}=1.9)$, those reporting carriage of heavy tumpline loads $(\mathrm{OR}=2.0)$ and those reporting that their lives were tough $(\mathrm{OR}=2.3)$. An association with low household consumption $(\mathrm{OR}=1.5)$, a proxy for relative poverty, was not quite significant. HADS-Depression total scores correlated positively with neuroticism $(r=0.32$; $p<0.001)$ and negatively with WHOQOL- $8(r=-0.50$; $p<0.001)$.

Only the positive association with marijuana use $(\mathrm{AOR}=3.6$ [95 \% CI: 1.2-10.5]; $p=0.018)$ and the negative association with WHOQOL-8 (AOR $=0.9$ [95 \% CI: $0.8-0.9$ ]; $p<0.001)$ survived the multivariate analysis.

HADS-cAD showed a similar ascending trend with age, significant after the age of 35 years (Table 2). In the bivariate analysis, HADS-cAD was more prevalent among females $(\mathrm{OR}=1.5)$, the widowed $(\mathrm{OR}=4.8)$, high-altitude dwellers $(\mathrm{OR}=2.0)$, tobacco users $(\mathrm{OR}=$ 1.7), daily tumpline users $(\mathrm{OR}=1.6)$, those carrying heavy tumpline loads $(\mathrm{OR}=1.7)$ and those reporting that life was tough $(\mathrm{OR}=6.1)$ (Table 2).
In the multivariate analysis, the associations with widowhood $(\mathrm{AOR}=2.7[95 \% \mathrm{CI}: 1.5-5.1] ; p=0.002)$ and high altitude dwelling (AOR $=2.3$ [95 \% CI: 1.43.9]; $p=0.002$ ) survived. Additionally, a positive association with urban dwelling (AOR $=2.4$ [95 \% CI: 1.4-3.9]; $p=0.001)$ and a negative association with alcohol use (AOR $=0.6$ [95 \% CI: $0.3-0.9] ; p=0.026)$ emerged. Multivariate analysis also uncovered a positive association of HADS-cAD with neuroticism (AOR $=1.3$ [95 \% CI: $1.2-1.4] ; p<0.001)$ and a negative association with WHOQOL-8 (AOR = 0.8 [95 \% CI: 0.75-0.84]; $p<0.001$ ).

There were no associations with BP or BMI.

\section{Discussion}

HADS-A was more prevalent among the Nepalese than HADS-D, while the two conditions were highly comorbid with each other. HADS-cAD showed significant associations with widowhood, urban and high-altitude dwelling and neuroticism. HADS-A, like HADS-cAD, was more prevalent among urban dwellers. All three types of caseness were associated with poorer QoL. However, comorbid cases containing all elements of both anxiety and depression were associated, more than cases of HADS-A or HADS-D only, with life complications such as those of urban or high-altitude dwelling, and widowhood. We say more about these later.

Owing to the high comorbidity between anxiety and depression, psychiatric research tends to report their combined prevalence: one recent review found the collective worldwide 1-year prevalence of these disorders to be almost $20 \%$ [5]. However, other recent global reviews have revealed prevalences separately of depression in the range $4.4-5.0 \%$ [33] and anxiety in the range 4.8$10.9 \%$ [34]. Our finding for HADS-D (5.2 \%) was at the upper limit of the global range, but for depression (ie, adding those cases included among HADS-cAD), at $11.7 \%$ (95 \% CI: 10.3-13.1), it was more than double. Our finding of $16.2 \%$ for HADS-A was already well above the global range, and for anxiety (adding those included in HADS-cAD), at 22.7 \% (95 \% CI: 20.9-24.5), it was again more than double. These findings are in keeping with the WHO Mental Health (WMH) survey [35], which showed anxiety disorders to be the most prevalent of all mental disorders, but suggest that, in Nepal, both depression and anxiety are excessively prevalent. 
We have exercised caution here, in using the word "suggest". It is the case that most of these reviews, as well as cross-national epidemiological studies [36], found both depression and anxiety to be more prevalent in the Western world than in less developed regions such as South Asia. While genetic, sociocultural, environmental and other factors might contribute to real differences, there are important methodological factors to consider that influence prevalence estimates. Commonly these relate to sampling methods, but of specific concern here are the instruments used. Most Western studies utilized diagnostic interviews, while surveys in the less-affluent world used symptom-based scales to screen for psychiatric caseness. Accordingly, HADS, which we used, is a screening instrument for estimating the point prevalences of anxiety and depression, and as such it has limitations. It detects the subjective manifestations of anxiety and depression [24], while vegetative or somatic symptoms of distress forming parts of the diagnostic classifications (DSM [37] or ICD [38]) may not be sufficiently captured. Surveys dependent on HADS and similar instruments may therefore underestimate actual prevalences, as has been discussed both in the review on CMDs [5] and in a WMH survey from China [39].

The Chinese study [39] emphasized the relevance of sociocultural protective factors (family structure, neighbourhood), which are believed to play a buffering role in most Asian countries [5], including Nepal, against the distress associated with anxiety or depression. In a different vein, stigma associated with the widespread belief that disclosure of mental illness might lead to embarrassment and discrimination is more common in underdeveloped societies, and may contribute towards underreporting of mental as opposed to physical symptoms; this too was evidenced in a WMH multicentre study [40]. Because these issues were likely to apply to our study, our findings of excessively prevalent depression and anxiety in Nepal appear even more remarkable since they were unlikely to be overestimates.

From the public-health perspective, the importance of their very high prevalences lies in the associations of both depression and anxiety with substantial disability. There is a wealth of evidence of this, including the data from GBD 2013 [4]: globally, major depressive disorders are the $2^{\text {nd }}$ highest cause of YLDs (51.8 million per year), and dysthymia, which is also expected to be captured by HADS-Depression, is $16^{\text {th }}$ (another 9.8 million YLDs per year); anxiety disorders are $9^{\text {th }}(24.4$ million YLDs per year). These GBD estimates are based on the global mean prevalences-well below those we have found in Nepal. In other words, the disability these disorders give rise to globally [4], great though it is, may not at population level match that in Nepal. Important also are our findings that all of HADS-A, HADS-D and HADS-cAD were associated with low QoL and high neuroticism, illustrations of their major effects on functioning at individual level.

With regard to associations, damage to family or social functioning is linked to mental ill health [41]. As evidence of this, we found HADS-cAD to be more prevalent among widows. Similarly, a cross-national survey [36], as well as two Asian studies-one from Iran [16] and one from China [42]-showed a high prevalence of CMDs among the widowed. Beyond the stress precipitated by a major family life event, widowhood entails substantial deviance in the societal role as well as in selfperception: widows perceive a lack of social support compared with those who are married [43].

Society is made up of households that are characteristic of the habitation where they stand. We found substantial associations between mental health and the location of the home: HADS-A and HADS-CAD were significantly more prevalent among the urban population, as was seen for the anxiety disorders in one of the global reviews [34]. Similarly, in India [44], multiple effects of unplanned urbanization including fast population growth, environmental degradation and sociocultural conflicts were cited as possible contributors of escalating mental-health problems, particularly depression and anxiety, among city populations. These may be applicable also in Nepal: decade-long political conflicts resulted in rapid migration of villagers into nearby cities, thus swiftly expanding the urban population [45]. In addition, other factors may lead to an increase in the prevalence of psychiatric disorders in the cities [46]: for example, the tendency of some mentally ill people to settle in towns rather than in the countryside, possibly to protect them from social stigma, to be away from the difficulties of rural life, to obtain proper care from social welfare institutions or better treatment, in search of jobs, or just to beg.

Habitation in Nepal also includes high hills and mountains, which cover almost one third of the total land area of the country [47]. So far, no study has explored psychiatric illnesses among the occupants of these territories. This was the first research in the South Asian Region to demonstrate the possible effect of geographical elevation on mental health. It showed HADS-cAD to be more prevalent above $2000 \mathrm{~m}$. Two studies in Peru [48, 49] and a US study [50] suggested the role of hypoxia and mitochondrial dysfunction as the possible link between altitude and depression. There are also studies on highaltitude ascenders from China [51] and among porters and trekkers in Nepal [52] that found anxiety to be one of the most recorded medical symptoms. But further work is necessary to elucidate whether biological conditions or psychosocial factors related to life adversity, isolation or the limited access to mental-health facilities in 
these areas are responsible for the mental-health problems.

Our findings of a negative association between alcohol use and HADS-A (as well as HADS-cAD), and of a positive relationship between marijuana use and HADS-D, need cautious interpretation. It is not so simple to capture the impact of alcohol use in a country like Nepal where drinking is considered an integral part of social functioning in most of the so-called Matwali community, which traditionally is prone to drinking [53]. Similarly, marijuana, which is also culturally accepted among the Nepalese, especially during certain religious functions [54], may not show its true relationship with mental health. We were unable fully to evaluate the potential relationships between substance dependence and mental health because the length of the questionnaire restricted us from adding more questions. Further studies are necessary in this area.

Contrary to global $[5,33,34]$ and local studies $[10,15,16]$, we found no gender associations. Perhaps the somatic symptoms that generally are reported more frequently by depressed females [55] were not sufficiently captured by HADS, which was originally constructed to detect emotional symptoms among hospital populations, and therefore pays less attention to bodily symptoms [24].

Although many studies have shown associations between poverty and CMDs in the LAMI countries [56], we did not find direct support for these. It may be that our questions on annual household consumption and monthly expenditure did not estimate well the socioeconomic status of the household; the responses may have been vaguely reported by the participants, many of whom were illiterate [30]. In Nepal, where people generally are poor [19], it is challenging to find a suitable measure of socioeconomic status in relation to CMD caseness. Income is not a reliable indicator, consumption cannot be assessed using direct monetary measures and proxy measures such as educational status have limited usefulness in this country with so much illiteracy; all these issues have been discussed in an earlier publication [20]. Nevertheless, our observation of high prevalence of both anxiety and depression among the Nepalese with relatively low socioeconomic status may well establish the link between poverty and mental ill-health. As concluded in a WMH survey, income inequality is a possible factor promoting chronic illnesses like depression [36], but more so in high-income countries than in the LAMI countries.

Our study was built upon tried and tested methodology [20], a large sample size, a very high participation rate achieved through careful sampling methodology [21], completeness of data and representativeness of the population's geographical and cultural diversities. These were the strengths of this study. The cross-sectional nature of the study obviously could not capture the longitudinal, relapsing and remitting course of depression and anxiety, or illustrate the temporal direction of associations with sociodemographic factors [36]. The limitations in the use of HADS rather than expert clinical interview have been discussed above. However, these are considerably offset: we believe culturally validated study instruments account for socially acceptable outcomes better than the ethnically insensitive diagnostic classifications relied upon in various cross-national [35] and global reviews [33].

\section{Conclusion}

Our study has opened a neglected research arena [18]. As a pioneering work in assessing prevalences of the most common mental disorders nationwide, it also brings out important implications for advancing the field of mental health in Nepal. We found that depression and anxiety were highly, perhaps excessively, prevalent in the country, while noting that these disorders are globally the second and ninth highest causes of disability. Also, we found that disadvantaged groups such as widows and those tolerating hardships and scarcity in the high hills were more affected. From the publichealth perspective, these are clear, compelling and urgent messages. Depression and anxiety must be among the health-care priorities in Nepal; there must be expansion, and wider delivery, of mental health care in the country. In view of the scarce resources, limited health budget and lack of specialized psychiatric services, integrating care for a substantial majority of those affected by these disorders into the fabric of national primary health-care services would be a reasonable goal.

\section{Ethics approval and consent to participate}

The study protocol was approved by the Nepal Health Research Council (NHRC), the Institutional Review Committee of Kathmandu University School of Medical Sciences, Dhulikhel Hospital (IRC-KUSMS), and The Central Regional Committee for Health and Research Ethics in Norway. Informed consent was given by all participants and confirmed either by signature or by fingerprint.

\section{Consent for publication}

Prior to the interview, all prospective participants were given written information approved by the ethics committees, which described in Nepali the nature and purpose of the study and the implications of taking part. This information clearly stated that consent to participation included consent to publication by the researchers of participants' anonymized data, which would be held at the Norwegian University of Science and Technology. 
Prospective participants who were literate read this information. To those who were illiterate, the interviewers read the information in the presence of family members.

\section{Availability of data and materials}

The data contributing to these analyses are held on a secure database at Norwegian University of Science and Technology (NTNU) in accordance with European dataprotection legislation and consents given by participants. Researchers or clinicians seeking access to these data for academic non-commercial purposes are welcome to submit a request to the corresponding author (AR). All such requests will be met whenever possible.

\begin{abstract}
Abbreviations
AOR: adjusted odds ratio; BP: blood pressure; BMI: body mass index; CAD: comorbid anxiety and depression; Cl: confidence interval; CMD: common mental disorder; DSM: diagnostic and statistical manual of mental disorders; EPQRS-N: eysenck personality questionnaire revised short form-neuroticism; GBD: Global Burden of Disease; HADS: Hospital Anxiety and Depression Scale; HARDSHIP: headache-attributed restriction, disability, social handicap and impaired participation; ICD: International Classification of Diseases; JNC: Joint National Committee; LAMI: low-and-middle-income; NHRC: Nepal Health Research Council; NTNU: Norwegian University of Science and Technology; OR: odds ratio; QoL: quality of life; SPSS: statistical package for social science; WHOQOL-8: World Health Organization Qualityof-Life 8-question scale; WMH: World Mental Health; YLD: year of life lost to disability.
\end{abstract}

\section{Competing interests}

The author declares that they have no competing interests.

\section{Authors' contributions}

Conception and design: AR, KM, ML, TS, AH. Acquisition of data: AR, KM, ML, TS, AH. Analysis and interpretation of data: AR, KM, ML, TS, AH. Drafting the article: AR. Revising it critically for important intellectual content: AR, KM, ML, TS, AH. Giving final approval of the version to be submitted: KM, ML, TS, AH. All authors read and approved the final manuscript.

\section{Acknowledgements}

The study was a research collaboration between NTNU Department of Neuroscience, Kathmandu University School of Medical Sciences (KUSMS), and Lifting The Burden, a UK-registered non-governmental organization directing the Global Campaign against Headache in official relations with the World Health Organization. We thank Dhulikhel Hospital, Kathmandu University Hospital, for assistance and logistic support during the planning phase.

\section{Funding}

This project was funded by grants from Samarbeidsorganet, the Liaison Committee between the Central Norway Regional Health Authority and the Norwegian University of Science and Technology (NTNU).

\section{Author details \\ 'Department of Neuroscience, Norwegian University of Science and Technology (NTNU), Trondheim, NO 7491, Norway. ${ }^{2}$ Dhulikhel Hospital, Kathmandu University Hospital, Dhulikhel, Kavre, Nepal. ${ }^{3}$ Norwegian Advisory Unit on Headaches, St Olavs University Hospital, Trondheim, Norway. ${ }^{4}$ Division of Brain Sciences, Imperial College London, London, UK. ${ }^{5}$ Pain Unit, St Olavs University Hospital, Trondheim, Norway.}

\section{Received: 28 October 2015 Accepted: 8 April 2016}

\section{Published online: 14 April 2016}

\section{References}

1. Goldberg D, Huxley P. Common mental disorders: a biosocial model. London: Tavistock/Routledge; 1992.

2. Risal A. Common mental disorders. Kathmandu Univ Med J. 2011;9(35):213-7.
3. Gustavsson A, Svensson M, Jacobi F, Allgulander C, Alonso J, Beghi E, et al. Cost of disorders of the brain in Europe 2010. Eur Neuropsychopharmacol. 2011;21(10):718-79.

4. Vos T, Barber RM, Bell B, Bertozzi-Villa A, Biryukov S, Bolliger I, et al. Global, regional, and national incidence, prevalence, and years lived with disability for 301 acute and chronic diseases and injuries in 188 countries, 1990-2013: a systematic analysis for the Global Burden of Disease Study 2013. Lancet. 2015;386(9995):743-800. doi:10.1016/s0140-6736(15)60692-4.

5. Steel Z, Marnane C, Iranpour C, Chey T, Jackson JW, Patel V, et al. The global prevalence of common mental disorders: a systematic review and metaanalysis 1980-2013. Int J Epidemiol. 2014;43(2):476-93. doi:10.1093/ije/ dyu038.

6. Wittchen HU, Jacobi F, Rehm J, Gustavsson A, Svensson M, Jonsson B, et al. The size and burden of mental disorders and other disorders of the brain in Europe 2010. Eur Neuropsychopharmacol. 2011;21(9):655-79. doi:10.1016/j. euroneuro.2011.07.018.

7. Phua HP, Chua AV, Ma S, Heng D, Chew SK. Singapore's burden of disease and injury 2004. Singapore Med J. 2009;50(5):468-78.

8. Mirza I, Jenkins R. Risk factors, prevalence, and treatment of anxiety and depressive disorders in Pakistan: systematic review. BMJ. 2004;328(7443):794. doi:10.1136/bmi.328.7443.794.

9. Kessler RC, Chiu WT, Demler O, Merikangas KR, Walters EE. Prevalence, severity, and comorbidity of 12-month DSM-IV disorders in the National Comorbidity Survey Replication. Arch Gen Psychiatry. 2005;62(6):617-27. doi:10.1001/archpsyc.62.6.617.

10. Khan H, Kalia S, Itrat A, Khan A, Kamal M, Khan MA, et al. Prevalence and demographics of anxiety disorders: a snapshot from a community health centre in Pakistan. Ann Gen Psychiatry. 2007;6:30. doi:10.1 186/1744-859x-6-30

11. Patel V, Pereira J, Coutinho L, Fernandes R, Fernandes J, Mann A. Poverty, psychological disorder and disability in primary care attenders in Goa, India. Br J Psychiatry. 1998;172:533-6.

12. Kohrt BA, Worthman CM. Gender and anxiety in Nepal: the role of social support, stressful life events, and structural violence. CNS Neurosci Ther. 2009;15(3):237-48. doi:10.1111/j.1755-5949.2009.00096.x.

13. Kohrt BA, Hruschka DJ, Worthman CM, Kunz RD, Baldwin JL, Upadhaya N, et al. Political violence and mental health in Nepal: prospective study. Br J Psychiatry. 2012;201(4):268-75. doi:10.1192/bjp.bp.111.096222.

14. Luitel NP, Jordans MJ, Sapkota RP, Tol WA, Kohrt BA, Thapa SB, et al. Conflict and mental health: a cross-sectional epidemiological study in Nepal. Soc Psychiatry Psychiatr Epidemiol. 2013;48(2):183-93. doi:10.1007/s00127-012-0539-0.

15. Jonas JB, Nangia V, Rietschel M, Paul T, Behere P, Panda-Jonas S. Prevalence of depression, suicidal ideation, alcohol intake and nicotine consumption in rural Central India. The Central India Eye and Medical Study. PLoS One. 2014;9(11):e113550. doi:10.1371/journal.pone.0113550.

16. Ahmadvand A, Sepehrmanesh Z, Ghoreishi FS, Afshinmajd S. Prevalence of psychiatric disorders in the general population of Kashan, Iran. Arch Iran Med. 2012;15(4):205-9. doi:012154/aim.006.

17. Risal A, Manandhar K, Linde M, Koju R, Steiner TJ, Holen A. Reliability and Validity of a Nepali-language Version of the Hospital Anxiety and Depression Scale (HADS). Kathmandu Univ Med J. 2015;50(2):115-24.

18. Razzouk D, Sharan P, Gallo C, Gureje O, Lamberte EE, de Jesus MJ, et al. Scarcity and inequity of mental health research resources in low-and-middle income countries: a global survey. Health Policy. 2010;94(3):211-20. doi:10.1016/j.healthpol.2009.09.009.

19. The World Bank Data-Country and Lending groups. 2014. http://data. worldbank.org/about/country-classifications/country-and-lending-groups. Accessed 28 Oct 2015

20. Risal A, Manandhar K, Steiner TJ, Holen A, Koju R, Linde M. Estimating prevalence and burden of major disorders of the brain in Nepal: cultural, geographic, logistic and philosophical issues of methodology. J Headache Pain. 2014;15(1):51. doi:10.1186/1129-2377-15-51.

21. Manandhar K, Risal A, Steiner TJ, Holen A, Koju R, Linde M. Estimating the prevalence and burden of major disorders of the brain in Nepal: methodology of a nationwide population-based study. J Headache Pain. 2014;15(1):52. doi:10.1186/1129-2377-15-52.

22. Manandhar K, Risal A, Steiner TJ, Holen A, Linde M. The prevalence of primary headache disorders in Nepal: a nationwide population-based study. J Headache Pain. 2015;16(1):95. doi:10.1186/s10194-015-0580-y.

23. Manandhar K, Risal A, Linde M, Steiner TJ. The burden of headache disorders in Nepal: estimates from a population-based survey. J Headache Pain. 2015;17(1):3. doi:10.1186/s10194-016-0594-0. 
24. Zigmond AS, Snaith RP. The hospital anxiety and depression scale. Acta Psychiatr Scand. 1983;67(6):361-70.

25. Manandhar K, Risal A, Linde M, Koju R, Steiner TJ, Holen A. Measuring neuroticism in Nepali: Reliability and validity of the Neuroticism Subscale of the Eysenck Personality Questionnaire. Kathmandu Univ Med J. 2015;50 (2):156-61.

26. Eysenck SBG, Eysenck HJ, Barrett P. A revised version of the psychoticism scale. Person Individ Difl. 1985;6(1):21-9.

27. The WHOQOL Group. The World Health Organization Quality of Life assessment (WHOQOL): Development and general psychometric properties. Soc Sci Med. 1998:46:1569-85.

28. Steiner TJ, Gururaj G, Andree C, Katsarava Z, Ayzenberg I, Yu S-Y, et al. Diagnosis, prevalence estimation and burden measurement in population surveys of headache: presenting the HARDSHIP questionnaire. J Headache Pain. 2014;15:3.

29. Stovner LJ, Al Jumah M, Birbeck GL, Gururaj G, Jensen R, Katsarava Z, et al. The methodology of population surveys of headache prevalence, burden and cost: Principles and recommendations from the Global Campaign against Headache. J Headache Pain. 2014;15(1):5. doi:10.1186/1129-2377-15-5.

30. Govenment of Nepal, Ministry of Health and Population, Population Division. Nepal Population Report 2011. Kathmandu: Ministry of Health and Population, Population Division; 2011.

31. Chobanian AV, Bakris GL, Black HR, Cushman WC, Green LA, Izzo Jr JL, et al. The Seventh Report of the Joint National Committee on Prevention, Detection, Evaluation, and Treatment of High Blood Pressure: the JNC 7 report. JAMA. 2003;289(19):2560-72. doi:10.1001/jama.289.19.2560.

32. Centers for Disease Control and Prevention. Healthy Weight - it's not a diet, it's a lifestyle! [database on the Internet] 2014. Available from: http://www. cdc.gov/healthyweight/assessing/bmi/adult_bmi/. Accessed: 28 Oct 2015

33. Ferrari AJ, Somerville AJ, Baxter AJ, Norman R, Patten SB, Vos T, et al. Global variation in the prevalence and incidence of major depressive disorder: a systematic review of the epidemiological literature. Psychol Med. 2013;43(3): 471-81. doi:10.1017/s0033291712001511.

34. Baxter AJ, Scott KM, Vos T, Whiteford HA. Global prevalence of anxiety disorders: a systematic review and meta-regression. Psychol Med. 2013;43 (5):897-910. doi:10.1017/s003329171200147x

35. Kessler RC, Aguilar-Gaxiola S, Alonso J, Chatterji S, Lee S, Ormel J, et al. The global burden of mental disorders: an update from the WHO World Mental Health (WMH) surveys. Epidemiol Psichiatr Soc. 2009;18(1):23-33.

36. Bromet E, Andrade LH, Hwang I, Sampson NA, Alonso J, de Girolamo G, et al. Cross-national epidemiology of DSM-IV major depressive episode. BMC Med. 2011;9:90. doi:10.1186/1741-7015-9-90.

37. American Psychiatric Association. Diagnostic and statistical manual of mental disorders (4th ed., text rev.) 2000. doi:10.1176/appi.books. 9780890423349 .

38. World Health Organization. The ICD-10 classification of mental and behavioural disorders: clinical descriptions and diagnostic guidelines. Geneva: World Health Organization; 1992.

39. Shen YC, Zhang MY, Huang YQ, He YL, Liu ZR, Cheng H, et al. Twelvemonth prevalence, severity, and unmet need for treatment of mental disorders in metropolitan China. Psychol Med. 2006;36(2):257-67. doi:10.1017/s0033291705006367.

40. Ahmedani BK, Kubiak SP, Kessler RC, de Graaf R, Alonso J, Bruffaerts R, et al. Embarrassment when illness strikes a close relative: a World Mental Health Survey Consortium Multi-Site Study. Psychol Med. 2013:43(10):2191-202. doi:10.1017/s003329171200298x.

41. Hecht H, von Zerssen D, Wittchen HU. Anxiety and depression in a community sample: the influence of comorbidity on social functioning. J Affect Disord. 1990;18(2):137-44.

42. Wong CK, Liang J, Chan ML, Chan YH, Chan L, Wan KY, et al. Prevalence and psychosocial correlates of depressive symptoms in urban Chinese women during midlife. PLoS One. 2014;9(11):e110877. doi:10.1371/journal.pone. 0110877.

43. Patel V, Kirkwood BR, Pednekar S, Pereira B, Barros P, Fernandes J, et al. Gender disadvantage and reproductive health risk factors for common mental disorders in women: a community survey in India. Arch Gen Psychiatry. 2006;63(4):404-13. doi:10.1001/archpsyc.63.4.404.

44. Trivedi JK, Sareen H, Dhyani M. Rapid urbanization - Its impact on mental health: A South Asian perspective. Indian J Psychiatry. 2008;50(3):161-5. doi:10.4103/0019-5545.43623.
45. Tol WA, Kohrt BA, Jordans MJ, Thapa SB, Pettigrew J, Upadhaya N, et al. Political violence and mental health: a multi-disciplinary review of the literature on Nepal. Soc Sci Med. 2010;70(1):35-44. doi:10.1016/j.socscimed. 2009.09.037.

46. Weich S, Twigg L, Lewis G. Rural/non-rural differences in rates of common mental disorders in Britain: prospective multilevel cohort study. $\mathrm{Br} \mathrm{J}$ Psychiatry. 2006;188:51-7. doi:10.1192/bjp.bp.105.008714.

47. Ministry of Health and Population (MOHP) [Nepal], New ERA, and ICF International Inc. Nepal Demographic and Health Survey 2011. Kathmandu: Ministry of Health and Population, New ERA, and ICF International, Calverton, Maryland; 2012.

48. Arregui A. Is depression more frequent in the altitude? A pilot study. Rev Med Hered. 1995;6:182-6.

49. Arregui A, Cabrera J, Leon-Velarde F, Vizcarra D, Umeres H, Acosta R, et al. Chronic mountain sickness, migraine and depression: Causal or fortuitous coexistence? Possible role of hypoxic environment. Rev Med Hered. 1995; 6:163-7.

50. DelMastro K, Hellem T, Kim N, Kondo D, Sung YH, Renshaw PF. Incidence of major depressive episode correlates with elevation of substate region of residence. J Affect Disord. 2011;129(1-3):376-9. doi:10.1016/j.jad.2010.10.001.

51. Dong JQ, Zhang JH, Qin J, Li QN, Huang W, Gao XB et al. Anxiety correlates with somatic symptoms and sleep status at high altitudes. Physiol Behav. 2013;112-113:23-31. doi:10.1016/j.physbeh.2013.02.001.

52. Basnyat B, Litch JA. Medical problems of porters and trekkers in the Nepal Himalaya. Wilderness Environ Med. 1997;8(2):78-81.

53. World Health Organization. Global Status Report on Alcoholand Health 2014 WHO, Geneva. 2014. WHO, Geneva. 2014. http://www.who.int/substance_ abuse/publications/global_alcohol_report/profiles/npl.pdf?ua=1. Accessed 11 Apr 2016.

54. Shrestha P. Policy initiatives for drug control in Nepal. Health. 2011;2(2):66-8

55. Silverstein B. Gender differences in the prevalence of somatic versus pure depression: a replication. Am J Psychiatry. 2002;159(6):1051-2.

56. Patel V, Araya R, de Lima M, Ludermir A, Todd C. Women, poverty and common mental disorders in four restructuring societies. Soc Sci Med. 1999; 49(11):1461-71.

\section{Submit your next manuscript to BioMed Central and we will help you at every step:}

- We accept pre-submission inquiries

- Our selector tool helps you to find the most relevant journal

- We provide round the clock customer support

- Convenient online submission

- Thorough peer review

- Inclusion in PubMed and all major indexing services

- Maximum visibility for your research

Submit your manuscript at www.biomedcentral.com/submit 